\title{
Determinants of Electricity Consumption Intensity in China: Analysis of Cities at Subprovince and Prefecture Levels in 2009
}

\author{
X. H. Xia ${ }^{1}$ and Yi Hu${ }^{2}$ \\ ${ }^{1}$ Institute of China's Economic Reform and Development, Renmin University of China, Beijing 100872, China \\ ${ }^{2}$ Academy of Mathematics and Systems Science, Chinese Academy of Sciences, Beijing 100190, China
}

Correspondence should be addressed to X. H. Xia, xia.email@yahoo.com.cn

Received 10 May 2012; Accepted 27 May 2012

Academic Editors: C. Bin and C. Zhan-Ming

Copyright (C) 2012 X. H. Xia and Y. Hu. This is an open access article distributed under the Creative Commons Attribution License, which permits unrestricted use, distribution, and reproduction in any medium, provided the original work is properly cited.

\begin{abstract}
China has experienced great social and economic vicissitudes that caused the vast complexity and uncertainty for electricity consumption. This paper attempts to identify the main determinants of the electricity consumption intensity by using the data from Chinese cities at subprovince and prefecture levels in 2009. The key category factors, including urban morphology, industrial structure, regulation context, urbanization degree, price, natural condition, and resource endowment, are abstracted and the influence of these determinants is evaluated by adopting the finite mixture models. The variation of each determinant across regions, the comparative weights of all the factors, and the detailed classifications of the cities are reported for facilitating the understanding of electricity consumption in China. The corresponding policies for electricity administration are addressed as well.
\end{abstract}

\section{Introduction}

Industrialization and urbanization are two distinguishing features in the present social and economic development of China. The rural-to-urban migration and changes in industrial and economic structure are regarded as two major factors which determine the electricity consumption and economic output. The cities at subprovince and prefecture levels especially districts under the jurisdiction of cities which are, in general, cores of the region, play the leading roles and have the dominant positions in the processes of social development.

In the hierarchy of the administrative divisions of China mainland, cities at subprovince and prefecture levels (hereinafter briefly called the cities) cover $47.859 \%$ of China's total land area, $87.260 \%$ of total population, and 93.903\% of Gross Regional Product (GRP), while 52.847\% of GRP, $49.843 \%$ of total investment in fixed assets, and $51.695 \%$ of local government revenue are concentrated in the districts under the jurisdiction of the cities with only $12.476 \%$ of population and $27.654 \%$ of land area of the cities in $2009[1,2]$. Meanwhile, the electricity consumption of the districts of the cities amounts to 1639.546 billion kwh which is about $44.273 \%$ of the total electricity consumption in China [2].

Prefecture level divisions (including subprovincial level, similarly hereinafter) are the second level of the administrative structure in the Constitution of China. The government at this level undertakes multiple responsibilities in terms of the administration of energy, economy, and environment issues.

The progress of urbanization and industrialization is always highly promoted by local governments, as it could bring about economic growth and better official performances which are two of the most important measures of GRP. Under the system of intergovernmental fiscal decentralization, about $52.400 \%$ of fiscal revenues are extracted by central government in 2009 [1]. The fiscal revenue of local government is another incentive to contest for output increase between different administrative divisions such as counties. As a general rule, the government at higher level is entitled to balance the development of the jurisdictional area. Hence the government at prefecture level is not only the implementer and promoter of urbanization and industrialization, but also the coordinator and participator of regional competition. 


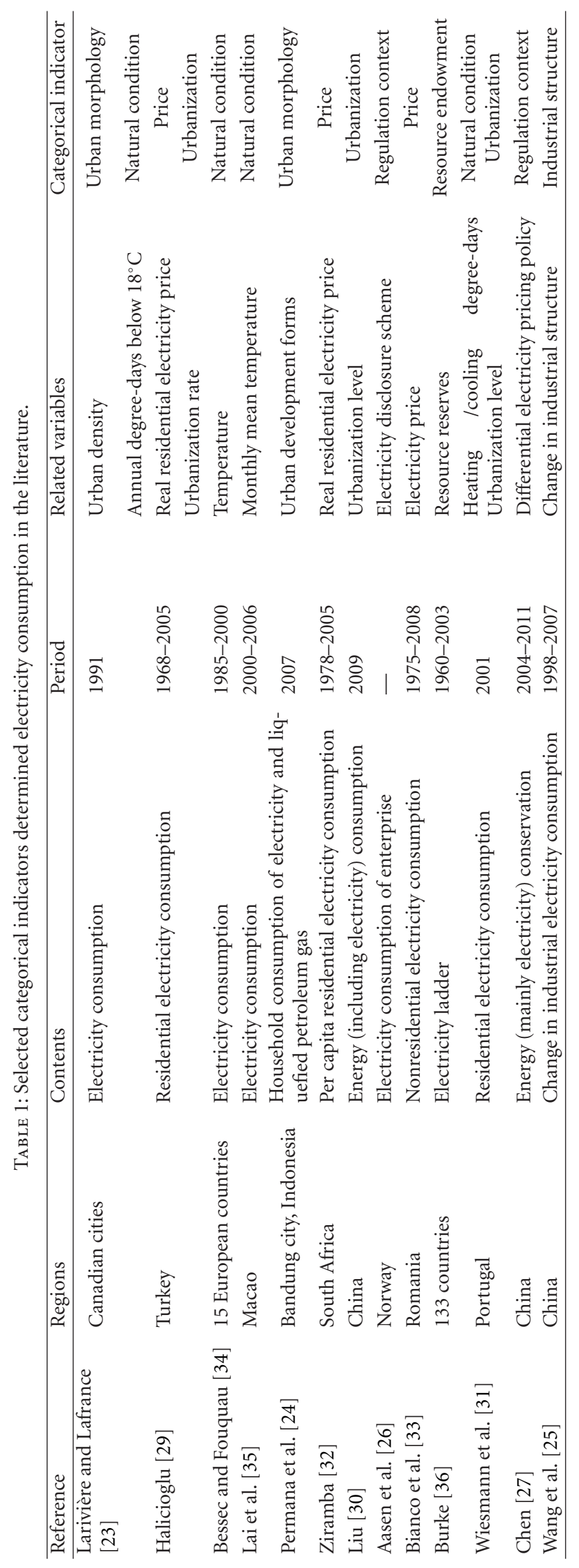


As a basic decision-making unit, the government at prefecture level is responsible for designing the layout of industry, especially that of small- and medium-sized enterprises (SMEs). For instance, the industrial park, being regarded as the incubator of local development, is often planned by government at this level. Meanwhile they also own the right to select industrial projects. In fact, the local government could reject the industrial settlement even programmed by the higher authorities for environmental or other reasons, or strive for it in order to earn more fiscal revenues when the projects are not settled. Thus the spatial arrangement of urban morphology and economy is mainly influenced and managed by authority at this level.

It is also a crucial node for the execution of energy policies including the regulation of electricity consumption in consideration of the more direct contact with local enterprises compared with higher authorities. The Chinese energy systems are intensively studied from the perspectives of international contexts $[3,4]$, provinces and regions $[5$, 6], macro systems [7-11], historical evolution [12, 13], and economic sectors $[14,15]$. Further study focusing on the analysis of divisions at the prefectural level could provide detailed information on the enforcement of the energy legislation, the motivation for the behavior of local government, and the heterogeneity and exogenous variables determining the electricity consumption.

As an efficient method allowing introducing unobservable heterogeneity, which exists largely in Chinese regions due to the unbalance of development in terms of electricity consumption, the finite mixture model has been widely used for capturing the different effects among variables in regressions and segregating samples for the convenience of analysis. The application of finite mixture models includes Beard et al. [16] for the identification of the technical diffusion and changing among US banks, Wedel and Desarbo [17] for the clustering of market segment on the satisfaction study in Europe, Yau et al. [18] for the estimation of the effects of pertinent factors which influenced the hospital neonatal length of stay in Austria, and Imai and Tingley [19] for the measuring the performance of rival theories. Considering the possibility of inaccurateness caused by statistical mistakes of migration population and the consistency with China's statistical system, the electricity intensity defined as the ratio of electricity to GRP is used as the indicator of electricity consumption in different areas. This paper aims to abstract the key factors determining the electricity consumption intensity of the cities at prefecture level in China, evaluate the influence of the processes of urbanization and industrialization on the electricity consumption intensity, compare the difference of these determinants' impact, and understand the channels through which each variable functions for policy makers.

\section{Literature Review}

The determinants of electricity consumption are extensively studied in much of the contemporary literature. Overall, seven factors which attracted great attention considering the influences of economic, social, and geographic contexts can be classified, as shown in, Table 1 .

Urban morphology refers to the characteristics of the spatial structure and the patterns of the regional economy. It is associated with many environmental topics as well, such as air pollution [20], land use [21], and urban conservation [22]. As for the electricity consumption, Larivière and Lafrance [23] demonstrated that raising the urban density which is defined as inhabitant per $\mathrm{km}^{2}$ could decrease the annual city electricity consumption per inhabitant in Canada. Permana et al. [24] confirmed the differences of energy consumption per unit income in three kinds of urban forms in Bandung City which is selected as a typical sample of developing country cities.

Industrial structure refers to the number and size distribution of enterprises. It causes significant impacts on the distribution of electricity consumption. Wang et al. [25] decomposed the determinant factors influencing the change trend of industrial electricity consumption in China and characterized these elements. Besides, the economic output, as well as the social and environmental function of different sectors, should be taken into consideration from the systematic perspectives [10]. For instance, Xia et al. [14] introduced the employment variable to evaluate the Chinese industrial sectors.

Regulation context is related to the institution backgrounds of environmental legislation, administration structure, and other settings. Aasen et al. [26] analyzed the influences of the electricity disclosure scheme required by the EU Electricity Directive on Norwegian enterprises and found out that the regulation policy may be inefficient because of the malfunction of program implementation. Chen [27] described the reform process of electricity pricing system proposed by China's central authorities and presented three difficulties of the current promotion for the conservation of energy consumption. The administration powers from the higher authorities are the mainspring of promoting energy efficiency and conservation in China. The regulation of energy consumption relies heavily on mandatory plans or other compulsory measures from above due to lacking of market mechanisms [28].

Urbanization rate is measured by the ratio of urban population to the total population. Since the urbanized area does not only include megalopolises, metropolises, but also small cities and towns, urbanization is different from the concentration of population which gives more attention to the central point of the city. For instance, a person who is living in a small town which is far from the central city and undertaking the production of mechanical instruments should be regarded as the urbanization population but not as the people concentrated in the district of the city. Halicioglu [29] found the longrun causality relationship between residential electricity consumption and urbanization in Turkey. Liu [30] studied the linkage between urbanization and energy consumption based on econometric methods including ARDL testing and ECM methods and proposed that urbanization acceleration may harmonize the sustainable development in China. Wiesmann et al. [31] also use the urbanization as an 
explanation variable to model the residential electricity consumption.

Price is bound up with the electricity utilization in terms of the demand and supply of electricity. As the instrument of market adjustment, price scheme together with other factors such as urbanization rate [29] impacts the selection of energy type of the individual and enterprises and eventually determines the amount of electricity consumption. Ziramba [32] estimated the price and income elasticities of residential electricity consumption, showing the price insensitivity of electricity demand in South Africa. Bianco et al. [33] forecasted the nonresidential electricity consumption based on the price analysis using trigonometric grey model.

Natural condition is a set of factors which could affect the producing and living conditions and influences the demand function of electricity consumption as the independent variable. For example, the necessity of heating, ventilation, and air condition system in the building absolutely depends on the temperature and humidity. Bessec and Fouquau [34] found the nonlinear relationship between temperature and electricity consumption and distinguished different patterns of this link in European countries by virtue of panel threshold model. Lai et al. [35] modeled the electricity consumption in Macao using mathematic methods and identified the quadratic influence of temperature on electricity consumption. The significance of temperature impacts on electricity was also reported by Larivière and Lafrance [23] and Wiesmann et al. [31].

Resource endowment is associated with the reserves of mineral, water, and other resources in the region, exerting great influence on the selection and development of industry and indirectly determining the electricity consumption. Burke [36] found that the electricity ladder which is defined by the transition from traditional electricity to renewable power relied heavily on the energy endowments after the investigation of 133 countries.

\section{Methodology and Data Descriptions}

3.1. Finite Mixture Model and PCA. The finite mixture model would be employed to identify the complexity of the electricity consumption in China and scrutinize the influence of the key factors mentioned before. The integration of factor analysis and clustering with category indicators are provided for implementing the policies of electricity administration. Let $y_{i}$ be the electricity consumption intensity (electricity consumption/GRP) observed for the city $i, i=1, \ldots, N$. The sample is assumed to be drawn from a finite mixture model with $K$ components. The probability density function for observations is given by

$$
f\left(y \mid X_{p}, X_{c}, \Pi, \Theta, \alpha\right)=\sum_{l=1}^{K} \Pi_{l}\left(X_{c}, \alpha\right) f_{l}\left(y \mid \Theta\left(X_{p}\right)\right)
$$

Here, $X_{p}$ denotes the predictor vector, $X_{c}$ is the concomitant variable vector, and $f(l=1, \ldots, K)$ indicates the component density function with the parameter vector $\Theta$. $\Pi_{l}$ represents the component weight and is defined in the $(K$ 1)-dimensional simplex as

$$
\sum_{l=1}^{K} \Pi_{l}\left(X_{c}, \alpha\right)=1, \quad 0<\Pi_{l}\left(X_{c}, \alpha\right)<1, \forall l
$$

where $\alpha=\left(\alpha_{l}^{\prime}\right)_{l=1, \ldots, K}^{\prime}$ is the parameter vector determining the probability of components. Suppose further that the model is the mixture of Gaussian linear regression, and (1) could be constructed as

$$
\begin{aligned}
& \sum_{l=1}^{K} \Pi_{l}\left(X_{c}, \alpha\right) N\left(y \mid \mu_{l}\left(X_{p}\right), \sigma_{l}^{2}\right) \\
& \quad=\sum_{l=1}^{K} \Pi_{l}\left(X_{c}, \alpha\right) N\left(y \mid X_{p}^{\prime} \beta_{l}, \sigma_{l}^{2}\right) .
\end{aligned}
$$

Here $\mu_{l}(\cdot)$ is the mean with linear structure $\mu_{l}(\cdot)=X_{p}^{\prime} \beta_{l}$ and $\sigma_{l}^{2}$ is the variance for the $l$ th component normal density $N\left(y \mid \mu_{l}\left(X_{p}\right), \sigma_{l}^{2}\right)$. The coefficients of mixture regression $\beta_{l}$ could be fixed across all the components, nested with some coefficients of components equally, or varied between the $K$ components. Maximum likelihood (ML) estimation could be used to fit the multivariate Gaussian linear mixture models through the ExpectationMaximization (EM) algorithm [37-40]. In computation practices the component weight $\Pi_{l}$ could be assumed to follow a multinomial logit model [41] as

$$
\Pi_{l}\left(X_{c}, \alpha\right)=\frac{\exp \left(X_{c}^{\prime} \alpha_{l}\right)}{\sum_{t} \exp \left(X_{c}^{\prime} \alpha_{t}\right)}, \quad \forall l
$$

with the constraint $\alpha_{1}=0$. Information criteria including Akaike Information Criterion (AIC) [42], Bayes Information Criterion (BIC) [43] and Hannan-Quinn Criterion (HQ) [44], and classification criteria including Normalized Entropy Criterion (NEC) [45], Classification Likelihood Criterion (CLC) [46] and Integrated Completed LikelihoodBIC (ICL-BIC) [47] are available for choosing the optimal structure of finite mixture models.

Principal component analysis, a linear dimension reduction method, is applied to combine the explanatory variables for the finite mixture model. This treatment was inspired by Bai and $\mathrm{Ng}$ [48] and $\mathrm{Ng}$ and Bai [49] and the analogous technique was also used in Xia et al. [14].

\subsection{Data Descriptions}

3.2.1. Data Definitions. As urban sprawl is generally developed from a specific focal point [50], the district concentration is a main feature of urban morphology. The district under the jurisdiction of the city is regarded as the focal point of the city, especially in China this district is normally the political, economical, and cultural center of the city. The concentrations of GRP $\left(X_{11}\right)$, population $\left(X_{12}\right)$, industrial value added $\left(X_{13}\right)$, fiscal revenue $\left(X_{14}\right)$, and investment in fixed assets $\left(X_{15}\right)$ are selected for measuring urban morphology as defined in Table 2. 
TABLE 2: Description of explanatory variables and category factors.

\begin{tabular}{|c|c|}
\hline Variable & Description \\
\hline \multicolumn{2}{|l|}{ Urban morphology $y^{\mathrm{a}}$} \\
\hline GRP concentration & The ratio of Gross Regional Product (GRP) of the district to that of the city \\
\hline Population concentration & The ratio of population of the district to that of the city \\
\hline Industrial concentration & The ratio of industrial value added of the district to that of the city \\
\hline Fiscal concentration & The ratio of government revenue by the district to that by the city \\
\hline Investment concentration & The ratio of total investment in fixed assets of the district to that of the city \\
\hline \multicolumn{2}{|l|}{ Industrial structure } \\
\hline Share of industrial output & The ratio of industrial value added to GRP in the city \\
\hline Share of industrial employment & $\begin{array}{l}\text { The ratio of the number of employed person in industry to the total of employed person } \\
\text { in the city }\end{array}$ \\
\hline Share of industrial electricity consumption & $\begin{array}{l}\text { The ratio of electricity consumption in local industry to the total of energy consumption } \\
\text { in the city }\end{array}$ \\
\hline
\end{tabular}

Regulation context

Decease rate of energy intensity

Decease rate of energy intensity of industry

Decease rate of electricity consumption intensity

Urbanization rate

Urbanization degree of the province

Share of nonagricultural population

Urbanization degree of the city

Electricity price

Average retail price of electricity

Natural condition

Annual average temperature

Resource endowment ${ }^{\mathrm{b}}$

Ensured reserves of iron ore

The decease rate of energy consumption per unit of GRP in local province in the corresponding period

The decease rate of energy consumption per unit of industrial value added in local province in the corresponding period

The decease rate of electricity consumption per unit of GRP in local province in the corresponding period

The proportion of urban population in the local province

The proportion of nonagricultural population in the city

The proportion of urban population in the city

The weighted average of industry, commerce, and residence prices

The mean of annual temperature according to urban temperature record in long term

${ }^{a}$ District refers to the districts under the jurisdiction of the city at subprovince and prefecture levels.

${ }^{\mathrm{b}}$ The effects of ensured reserves of coal which had been also taken into account are not significant. The resource endowment of the city may be disturbed by the coal transportation, while the iron ore is often utilized locally in China.

The shares of industrial output $\left(X_{21}\right)$, industrial employment $\left(X_{22}\right)$, and industrial electricity consumption $\left(X_{23}\right)$ are evaluated by the ratio of industrial value added to GRP, the ratio of industrial employment to total labor population and the weight of industrial electricity consumption in the city respectively. These indicators embody the aspects of economic, social, and environmental impacts and could give a comprehensive description of industrial structure $\left(X_{2}\right)$.

The energy intensity and electricity consumption intensity are the main indicators to be supervised by Chinese energy regulatory system and official statistical bureau. The former one becomes a constraint target in national development programs such as the 12th Five-Year Plan; the latter would be easily monitored in the view of government authorities and also treated as a relatively accurate indicator to reflect the actual conditions of energy consumption due to fewer incentives to manipulate the data on electricity consumption in comparison with those on energy consumption. The decease rates of energy intensity $\left(X_{31}\right)$, energy intensity of industry $\left(X_{32}\right)$, and electricity consumption intensity $\left(X_{33}\right)$ in the province are taken into consideration comprehensively to evaluate the regulation pressure which is exerted by provincial governments on the city authorities for the reflection of regulation context $\left(X_{3}\right)$.

The urbanization rate of the province $\left(X_{41}\right)$ is used to capture the provincial heterogeneity in the development due to uneven economic development in China. Since the urbanization process is often closely associated with the transfer of rural surplus labor to urban sectors, the share of nonagricultural population $\left(X_{42}\right)$ is chosen to measure industrial dimension of urbanization. The combination of the urbanization rate of the city $\left(X_{43}\right)$ and the other two variables could overcome the possible statistical bias coming from the incorrect estimated flowing population and gives a comprehensive evaluation of the categorical factor $X_{4}$, that is, urbanization $\left(X_{4}\right)$.

Average retail price of electricity which is the synthesis of all kinds of price including residential price, commercial 
TABLE 3: Descriptive statistics and units of original data.

\begin{tabular}{|c|c|c|c|c|c|}
\hline Variable & Unit & Mean & Standard deviation & Minimum & Maximum \\
\hline Output concentration $\left(X_{11}\right)$ & $\%$ & 45.533 & 23.585 & 8.038 & 100.000 \\
\hline Population concentration $\left(X_{12}\right)$ & $\%$ & 33.224 & 22.877 & 4.368 & 100.000 \\
\hline Industrial concentration $\left(X_{13}\right)$ & $\%$ & 48.899 & 25.140 & 5.447 & 100.000 \\
\hline Fiscal concentration $\left(X_{14}\right)$ & $\%$ & 52.600 & 25.490 & 5.931 & 100.000 \\
\hline Investment concentration $\left(X_{15}\right)$ & $\%$ & 45.047 & 23.766 & 7.300 & 100.000 \\
\hline Share of industrial output $\left(X_{21}\right)$ & $\%$ & 50.378 & 11.814 & 9.740 & 82.390 \\
\hline Share of industrial employment $\left(X_{22}\right)$ & $\%$ & 45.419 & 15.178 & 6.550 & 79.450 \\
\hline Share of industrial electricity consumption $\left(X_{23}\right)$ & $\%$ & 65.964 & 18.926 & 7.243 & 98.839 \\
\hline Decease rate of energy intensity $\left(X_{31}\right)$ & $\%$ & 4.908 & 2.295 & 0.830 & 9.730 \\
\hline Decease rate of energy intensity of industry $\left(X_{32}\right)$ & $\%$ & 8.984 & 3.057 & 0.030 & 15.100 \\
\hline Decease rate of electricity consumption intensity $\left(X_{33}\right)$ & $\%$ & 5.330 & 0.812 & 2.810 & 6.970 \\
\hline Urbanization degree of the province $\left(X_{41}\right)$ & $\%$ & 46.903 & 8.743 & 29.890 & 63.400 \\
\hline Share of nonagricultural population $\left(X_{42}\right)$ & $\%$ & 61.423 & 25.211 & 13.480 & 100.000 \\
\hline Urbanization degree of the city $\left(X_{43}\right)$ & $\%$ & 44.321 & 14.790 & 13.840 & 100.000 \\
\hline Average retail price of electricity $\left(X_{5}\right)$ & Yuan/MWH & 512.013 & 85.014 & 298.630 & 699.400 \\
\hline Annual average temperature $\left(X_{6}\right)$ & ${ }^{\circ} \mathrm{C}$ & 14.653 & 5.294 & -1.880 & 25.500 \\
\hline Ensured reserves of iron ore $\left(X_{7}\right)$ & 100 million tons & 9.916 & 16.698 & 0.000 & 70.200 \\
\hline
\end{tabular}

Note. Some maximum values of concentration variables are $100 \%$ because of the fulfillment of urbanization in some region.

price, and industrial price in China is chosen as an integrative indicator to measure the factor price $\left(X_{5}\right)$.

Since temperature is one of the most important factors affecting the electricity consumption as presented in literature, on account of the availability of data, annual average temperature which is recorded in climatological data is selected to measure the characteristics of natural condition $\left(X_{6}\right)$.

In view of the dependence of manufacture industry in China's economic growth and the high growth in demand for mineral resource, ensured reserves of iron ore could be proxy for resource endowment $\left(X_{7}\right)$.

3.2.2. Data Sources. The main data sources are China Statistical Yearbook and China City Statistical Yearbook, published by National Bureau of Statistics of China (NBSC). The variables associated with provincial characteristics are taken from NBSC [1] and those associated with city characteristics are abstracted from NBSC [2]. After removing the data with missing explanation variables, a final sample set of 277 cities including 15 cities at subprovince level and 262 cities at prefecture level in 2009 is obtained. The annual average temperature of each city is collected by the authors from public data sources such as the official website of local government. The average retail prices of electricity in the cities are drawn from the report of State Electricity Regulatory Commission [51].

3.2.3. Sample Description. The descriptive statistics and units of original data are given in Table 3 . The great disparity between regions in China exists in consideration of concentration degree. The minimum values of concentration variables are below $10 \%$ while the maximum values of these reach to $100 \%$, showing the spatial differences in Chinese urban development. The mean shares of industrial output, employment, and electricity consumption in industry are $50.378 \%, 45.419 \%$, and $65.964 \%$, respectively, indicating the high weight of electricity consumption in industry even if the output and employment contributions are accounted. Seeing that the average decease rate of industrial energy intensity $(8.984 \%)$ is smaller than that of total energy intensity $(4.908 \%)$ at the provincial level during the same period, the energy consumption of industry presents more elasticity than other sectors. The lowest retail price of electricity (298.630 Yuan/MWH) is only about $42.698 \%$ of the highest one (699.400 Yuan/MWH) in 2009. Despite the fact that the electricity price is regulated by Chinese government, price mechanism may play certain roles in resource allocations.

\section{Results and Discussion}

4.1. Dimensionality Reduction. Dimensionality reduction technique could provide crucial variables for understanding the key phenomena of interest without losing the information conveyed by the original data. The results of combined factors via PCA method could be given by

$$
\begin{gathered}
X_{1}=0.977 X_{11}+0.924 X_{12}+0.935 X_{13}+0.905 X_{14}+0.955 X_{15} \\
X_{2}=0.895 X_{21}+0.847 X_{22}+0.776 X_{23} \\
X_{3}=0.493 X_{31}+0.841 X_{32}+0.927 X_{33} \\
X_{4}=0.747 X_{41}+0.842 X_{42}+0.786 X_{43}
\end{gathered}
$$

The selected principle components of urban morphology $\left(X_{1}\right)$, industrial structure $\left(X_{2}\right)$, regulation context $\left(X_{3}\right)$ and urbanization rate $\left(X_{4}\right)$ extracted $88.242 \%, 70.724 \%$, $60.356 \%$, and $62.840 \%$ of squared loading sums, respectively. 
TABLE 4: Estimation results and variable structure for the finite mixture model ${ }^{\mathrm{a}}$.

\begin{tabular}{|c|c|c|c|c|c|}
\hline \multirow[t]{2}{*}{ Variable } & \multirow[t]{2}{*}{ Structure } & \multicolumn{4}{|c|}{ Coefficient estimates } \\
\hline & & Component 1 & Component 2 & Component 3 & Component 4 \\
\hline \multicolumn{6}{|c|}{ Predictor } \\
\hline Intercept & Varied & $\begin{array}{c}5461.407^{* * *} \\
(919.115)\end{array}$ & $\begin{array}{c}379.656^{* * * *} \\
(87.482)\end{array}$ & $\begin{array}{c}1774.662^{* * *} \\
(158.055)\end{array}$ & $\begin{array}{c}982.128^{* * *} \\
(61.198)\end{array}$ \\
\hline$X_{1}$ & Varied & $\begin{array}{c}113.915^{* * *} \\
(40.749)\end{array}$ & $\begin{array}{c}23.923^{* * *} \\
(2.821)\end{array}$ & $\begin{array}{c}59.830 * * * \\
(6.378)\end{array}$ & $\begin{array}{c}40.738^{* * *} \\
(3.021)\end{array}$ \\
\hline$X_{2}$ & Varied & $\begin{array}{c}66.189 \\
(92.219)\end{array}$ & $\begin{array}{c}22.124^{* * *} \\
(6.895)\end{array}$ & $\begin{array}{c}48.875^{* * *} \\
(12.326)\end{array}$ & $\begin{array}{c}32.844^{* * *} \\
(4.232)\end{array}$ \\
\hline$X_{3}$ & Fixed & $\begin{array}{c}-9.677^{* *} \\
(4.896)\end{array}$ & $\begin{array}{c}-9.677^{* *} \\
(4.896)\end{array}$ & $\begin{array}{c}-9.677^{* *} \\
(4.896)\end{array}$ & $\begin{array}{c}-9.677^{* *} \\
(4.896)\end{array}$ \\
\hline$X_{4}$ & Nested & $\begin{array}{c}19.305^{* * *} \\
(7.366)\end{array}$ & $\begin{array}{c}19.305^{* * *} \\
(7.366)\end{array}$ & $\begin{array}{c}17.365^{* *} \\
(6.991)\end{array}$ & $\begin{array}{c}17.365^{* *} \\
(6.991)\end{array}$ \\
\hline$X_{5}$ & Varied & $\begin{array}{c}-7.509^{* * *} \\
(1.315)\end{array}$ & $\begin{array}{l}-0.287 \\
(0.185)\end{array}$ & $\begin{array}{c}-2.910^{* * *} \\
(0.414)\end{array}$ & $\begin{array}{c}-0.759^{* * *} \\
(0.130)\end{array}$ \\
\hline$X_{6}$ & Varied & $\begin{array}{l}-52.716 \\
(35.108)\end{array}$ & $\begin{array}{c}6.815^{* *} \\
(2.750)\end{array}$ & $\begin{array}{c}25.498^{* * *} \\
(7.160)\end{array}$ & $\begin{array}{c}-7.531^{* * *} \\
(1.774)\end{array}$ \\
\hline \multicolumn{6}{|c|}{ Concomitant variable } \\
\hline Intercept & Varied & - & $\begin{array}{c}2.187^{* * *} \\
(0.441)\end{array}$ & $\begin{array}{c}1.976^{* * *} \\
(0.473)\end{array}$ & $\begin{array}{c}2.285^{* * *} \\
(0.516)\end{array}$ \\
\hline$X_{7}$ & Varied & - & $\begin{array}{c}-0.032^{* * *} \\
(0.012)\end{array}$ & $\begin{array}{c}-0.062^{* *} \\
(0.024)\end{array}$ & $\begin{array}{c}-0.186^{* *} \\
(0.092)\end{array}$ \\
\hline
\end{tabular}

${ }^{a}$ The standard errors of coefficient estimates are in parentheses. ${ }^{* *}$ and ${ }^{* * *}$ denote significance at $5 \%$ and $1 \%$ levels, respectively. All the explanatory variables are standardized.

4.2. Estimation Results. Considering the commonness of BIC $[14,49]$ and the robustness of ICL-BIC [47], the two criteria are used for appraising the fitting of mixture models. Table 4 shows the estimation results for the finite mixture model with best performance of fitting.

It is notable that the acting structure of factors that impacted on the electricity intensity is distinguishable across the components which are corresponding to the city clusters as shown in Table 5. The factors of urban morphology $\left(X_{1}\right)$, industrial structure $\left(X_{2}\right)$, price $\left(X_{5}\right)$, natural condition $\left(X_{6}\right)$, and resource endowment $\left(X_{7}\right)$ present variance between components, while the influence of regulation pressure $\left(X_{3}\right)$ is fixed and the impact of urbanization degree $\left(X_{4}\right)$ shows a nest structure. Meanwhile, the factor of resource endowment $\left(X_{7}\right)$ is modeled in the finite mixture model as a concomitant variable, indicating this factor influences the electricity intensity indirectly, whereas the other factors as predictors make more direct impacts on the dependent variable.

The estimations of each factor would be analyzed next. The positive coefficients on urban morphology $\left(\mathrm{X}_{1}\right)$ which is related to the urban concentration degree suggest that promoting the urban concentration would increase the electricity intensity. The moderate concentration of region would bring about economies of scale in the sense of electricity consumption, while the urban sprawling around a central point immoderately would vanish the scale merits and cause diseconomies of scale. The estimated results manifest the excess centralization of urban expansion in China. This centralized trend is most significant in the component 1 with the largest estimated coefficient which is evaluated cluster 1 of cities.

The extent of industrial structure $\left(X_{2}\right)$ impacts on electricity intensity is in keeping with that of urban morphology $\left(X_{1}\right)$. That is, as for the electricity intensity, the higher marginal contribution of urban concentration means the greater marginal influence of the rise of industrial weights as viewed from the sizes of estimated coefficients between the categorical factors. It is the evidence that the highly centered development in regions is partially attributed to the significant dependence on industrial output. The combined function of these factors leads to the increasing of electricity intensity and the boost of electricity demand.

The estimated coefficients of -9.677 on regulation context $\left(X_{3}\right)$ suggest that the administrative pressure from the higher level authorities on electricity consumption is the powerful measure to induce decreasing the electricity consumption intensity. Furthermore, as the estimation values are equal between the components, the validity of regulation pressure is identical across the cities owing to the homogeneity of administration system in China. The administration power from top to bottom is still a useful but expedient approach in the context of lacking long-term mechanisms for energy savings.

Regarding the urbanization rate $\left(X_{4}\right)$, the impacts on electricity consumption intensity presented two levels as the coefficients of 19.305 and 17.365 illustrated. The variables are standardized before estimation, so the impact extents could be compared. The signs of estimates betoken the possibility of long-term increasing of energy consumption intensity due 
TABLE 5: Clustering membership of the finite mixture model.

Cluster 1

Wuhai (Inner Mongolia), Anshan (Liaoning), Fushun (Liaoning), Benxi (Liaoning), Yingkou (Liaoning), Fuxin (Liaoning), Liaoyang (Liaoning), Huludao (Liaoning), Laiwu (Shandong), Jiaozuo (Henan), Panzhihua (Sichuan), Qujing (Guizhou), Tongchuan (Shaanxi), Jiayuguan (Gansu), Baiyin (Gansu), Shizuishan (Ningxia), Zhongwei (Ningxia)

Cluster 2

Shijiazhuang (Hebei), Handan (Hebei), Baoding (Hebei), Cangzhou (Hebei), Langfang (Hebei), Hengshui (Hebei), Jincheng (Shanxi), Shuozhou (Shanxi), Luliang (Shanxi), Hohhot (Inner Mongolia), Erdos (Inner Mongolia), Hulunbuir (Inner Mongolia), Bayannur (Inner Mongolia), Ulanqab (Inner Mongolia), Shenyang (Liaoning), Dalian (Liaoning), Dandong (Liaoning), Jinzhou (Liaoning), Panjin (Liaoning), Tieling (Liaoning), Chaoyang (Liaoning), Changchun (Jilin), Liaoyuan (Jilin), Baishan (Jilin), Songyuan (Jilin), Baicheng (Jilin), Harbin (Heilongjiang), Jiamusi (Heilongjiang), Wuxi (Jiangsu), Suzhou (Jiangsu), Nantong (Jiangsu), Lianyungang (Jiangsu), Yancheng (Jiangsu), Taizhou (Jiangsu), Suqian (Jiangsu), Zhoushan (Zhejiang), Hefei (Anhui), Wuhu (Anhui), Huangshan (Anhui), Chuzhou (Anhui), Bozhou (Anhui), Xuancheng (Anhui), Fuzhou (Fujian), Xiamen (Fujian), Putian (Fujian), Quanzhou (Fujian), Longyan (Fujian), Ningde (Fujian), Nanchang (Jiangxi), Jingdezhen (Jiangxi), Fuzhou (Jiangxi), Jinan (Shandong), Qingdao (Shandong), Zaozhuang (Shandong), Dongying (Shandong), Yantai (Shandong), Weifang (Shandong), Taian (Shandong), Weihai (Shandong), Dezhou (Shandong), Liaocheng (Shandong), Xuchang (Henan), Luohe (Henan), Zhoukou (Henan), Xiangfan (Hubei), Xiaogan (Hubei), Changsha (Hunan), Changde (Hunan), Yiyang (Hunan), Guangzhou (Guangdong), Heyuan (Guangdong), Yangjiang (Guangdong), Jieyang (Guangdong), Beihai (Guangxi), Fangchenggang (Guangxi), Yulin (Guangxi), Chengdu (Sichuan), Zigong (Sichuan), Luzhou (Sichuan), Deyang (Sichuan), Mianyang (Sichuan), Suining (Sichuan), Neijiang (Sichuan), Nanchong (Sichuan), Meishan (Sichuan), Yibin (Sichuan), Guangan (Sichuan), Dazhou (Sichuan), Bazhong (Sichuan), Ziyang (Sichuan), Yuxi (Guizhou), Baoshan (Guizhou), Lincang (Guizhou), Xi'an (Shaanxi), Baoji (Shaanxi), Xianyang (Shaanxi), Weinan (Shaanxi), Yan'an (Shaanxi), Hanzhong (Shaanxi), Yulin (Shaanxi), Shangluo (Shaanxi), Jiuquan (Gansu), Qingyang (Gansu)

Cluster 3

Tangshan (Hebei), Qinhuangdao (Hebei), Xingtai (Hebei), Zhangjiakou (Hebei), Chengde (Hebei), Yangquan (Shanxi), Yuncheng (Shanxi), Hegang (Heilongjiang), Daqing (Heilongjiang), Quzhou (Zhejiang), Maanshan (Anhui), Tongling (Anhui), Xinyu (Jiangxi), Zibo (Shandong), Rizhao (Shandong), Zhengzhou (Henan), Luoyang (Henan), Anyang (Henan), Shangqiu (Henan), Huangshi (Hubei), Ezhou (Hubei), Xiangtan (Hunan), Zhangjiajie (Hunan), Huaihua (Hunan), Shaoguan (Guangdong), Shantou (Guangdong), Dongguan (Guangdong), ZhongShan (Guangdong), Guigang (Guangxi), Baise (Guangxi), Hezhou (Guangxi), Laibin (Guangxi), Guangyuan (Sichuan), Leshan (Sichuan), Yaan (Sichuan), Guiyang (Guizhou), Zunyi (Guizhou), Anshun (Guizhou), Lanzhou (Gansu), Zhangye (Gansu), Pingliang (Gansu), Xining (Qinghai), Wuzhong (Ningxia)

Cluster 4

Taiyuan (Shanxi), Datong (Shanxi), Changzhi (Shanxi), Jinzhong (Shanxi), Xinzhou (Shanxi), Linfen (Shanxi), Baotou (Inner Mongolia), Chifeng (Inner Mongolia), Tongliao (Inner Mongolia), Jilin (Jilin), Siping (Jilin), Tonghua (Jilin), Qiqihar (Heilongjiang), Jixi (Heilongjiang), Shuangyashan (Heilongjiang), Yichun (Heilongjiang), Qitaihe (Heilongjiang), Mudanjiang (Heilongjiang), Heihe (Heilongjiang), Suihua (Heilongjiang), Nanjing (Jiangsu), Xuzhou (Jiangsu), Changzhou (Jiangsu), Huaian (Jiangsu), Yangzhou (Jiangsu), Zhenjiang (Jiangsu), Hangzhou (Zhejiang), Ningbo (Zhejiang), Wenzhou (Zhejiang), Jiaxing (Zhejiang), Huzhou (Zhejiang), Shaoxing (Zhejiang), Jinhua (Zhejiang), Taizhou (Zhejiang), Lishui (Zhejiang), Bengbu (Anhui), Huainan (Anhui), Huaibei (Anhui), Anqing (Anhui), Fuyang (Anhui), Suzhou (Anhui), Chaohu (Anhui), Liuan (Anhui), Chizhou (Anhui), Sanming (Fujian), Zhangzhou (Fujian), Nanping (Fujian), Pingxiang (Jiangxi), Jiujiang (Jiangxi), Yingtan (Jiangxi), Ganzhou (Jiangxi), Jian (Jiangxi), Yichun (Jiangxi), Shangrao (Jiangxi), Jining (Shandong), Linyi (Shandong), Binzhou (Shandong), Heze (Shandong), Kaifeng (Henan), Pingdingshan (Henan), Hebi (Henan), Xinxiang (Henan), Puyang (Henan), Sanmenxia (Henan), Nanyang (Henan), Xinyang (Henan), Zhumadian (Henan), Wuhan (Hubei), Shiyan (Hubei), Yichang (Hubei), Jingmen (Hubei), Jingzhou (Hubei), Huanggang (Hubei), Xianning (Hubei), Suizhou (Hubei), Zhuzhou (Hunan), Hengyang (Hunan), Shaoyang (Hunan), Yueyang (Hunan), Chenzhou (Hunan), Yongzhou (Hunan), Loudi (Hunan), Shenzhen (Guangdong), Zhuhai (Guangdong), Foshan (Guangdong), Jiangmen (Guangdong), Zhanjiang (Guangdong), Maoming (Guangdong), Zhaoqing (Guangdong), Huizhou (Guangdong), Shanwei (Guangdong), Qingyuan (Guangdong), Chaozhou (Guangdong), Nanning (Guangxi), Liuzhou (Guangxi), Guilin (Guangxi), Wuzhou (Guangxi), Qinzhou (Guangxi), Hechi (Guangxi), Chongzuo (Guangxi), Haikou (Hainan), Sanya (Hainan), Liupanshui (Guizhou), Kunming (Guizhou), Zhaotong (Guizhou), Lijiang (Guizhou), Puer (Guizhou), Ankang (Shaanxi), Tianshui (Gansu), Wuwei (Gansu), Dingxi (Gansu), Longnan (Gansu), Yinchuan (Ningxia), Guyuan (Ningxia)

to the urbanization trends in China, but the influences of the factor are inferior to those of urban morphology $\left(X_{1}\right)$ and industrial structure $\left(X_{2}\right)$.

The electricity consumption intensity is sensitive to the price of electricity $\left(X_{5}\right)$ in most regions in spite of the fact that the electricity price is regulated and controlled by the government administration. The coefficient of -7.509 on the electricity price $\left(X_{5}\right)$ in component 1 indicates that the enhancement of the electricity price may largely reduce the electricity consumption intensity of the regions in cluster 1 . The detailed examination of cluster 1 in Table 5 reveals that most of these cities abound with mineral deposits and rely on resource intensive industry for economic development. This is the evidence of the distortion of electricity price which may induce the discordances of industrial structure such as the overdevelopment of electricity intensive industry.

As the key variable indicated the natural condition the annual average temperature $\left(X_{6}\right)$ affects the utilization 
of electricity significantly in the region of clusters $2-4$. The values of $-0.032,-0.062$, and -0.186 on ensured reserves of iron ore $\left(X_{7}\right)$ give the detailed description of the cluster probability which is determined by the concomitant variable. It is revealed by the coefficients that the regions in cluster 1 are most related with the endowment in electricity consumption, followed by the regions in cluster 2 , cluster 3 , and cluster 4 in order. The industrial structure may be the intermediate link which could explain the indirection of the connection between electricity consumption intensity and the resource endowment. These findings show that the industry distribution near the ore sources is one of the characteristics in China and the influence degrees of the determinants of electricity consumption intensity may be varied with the resource endowment.

\section{Conclusions and Policy Implications}

This study extracts the key factors which determine the electricity consumption intensity of the cities at subprovince and prefecture levels and reveals the acting structure and extent of each determinant which reflects the main characteristics of Chinese social and economic development. The findings of this study are crucial for electricity administration and the specific policies are suggested as follows.

(1) Scrutinizing the underlying influences of potential actions before decision making and formulating the comprehensive policy in consideration of regional characteristics may cause better results. The unitary policy may distort the aims of the policymakers and even upset the initial targets because of the vast spread of development degrees and various effects of different factors.

(2) Optimizing the spatial layout of regional development would improve the efficiency of electricity consumption and decrease the electricity intensity. Since the GPR, population, industry, public finance, and investment are highly concentrated around the core areas of the cities in China, decentralization of regional planning should be taken into account to upgrade the performance of electricity utilization. It is necessary for the government to balance the economic and social development within the regions.

(3) Diversifying the industrial structure, decentralizing economic activities, and establishing multiple cores for regional development would be helpful to achieve lower growth of electricity intensity in China. The integrated consideration of industrial distribution and regional cooperation is needed for the sustainability of economic growth. These immediate actions should be taken especially for the regions in cluster 1 which is most related to the mineral dependent cities.

(4) Besides the regulation powers from the administrative systems, the synthetic system with multiple policy instruments should be established. More attention should be paid to the market oriented mechanism. Also, the price system should be given full scope to adjust the relationship between electricity consumption and economic activities.

(5) Promoting the urbanization in decentralization way and increasing the employment capacities of industry could relieve the pressure on electricity caused by urbanization in China. The influences of the regional concentrating and industry intensifying are greater than that of the urbanization in development. More attention should be paid on the former factors in order to manage the electricity consumption.

(6) Deregulating the electricity price and accelerating the market-oriented reform in energy field could phase down the distortion possibility of energy price system. Extending the industrial chains could lower the electricity consumption in the regions where the development is heavily relied on energy intensive industries. Meanwhile, the unitary energy policy within the country with a vast territory and various degrees of development as China may lead to unrealized results. Energy policies should be synthesized and the multiple factors should be considered adequately before implementation.

\section{Appendix}

See Table 5 .

\section{Acknowledgments}

This study has been supported by the Fundamental Research Funds for the Central Universities, and the Research Funds of Renmin University of China (Grant no. 12XNF017).

\section{References}

[1] NBSC (National Bureau of Statistics of China), China Statistical Yearbook 2010, China Statistical Press, Beijing, China, 2011.

[2] NBSC (National Bureau of Statistics of China), China City Statistical Yearbook 2010, China Statistical Press, Beijing, China, 2011.

[3] Z. Zhang, "The U.S. proposed carbon tariffs, WTO scrutiny and China's responses," International Economics and Economic Policy, vol. 7, no. 2, pp. 203-225, 2010.

[4] J. Guo, L. L. Zou, and Y. M. Wei, "Impact of inter-sectoral trade on national and global $\mathrm{CO}_{2}$ emissions: an empirical analysis of China and US," Energy Policy, vol. 38, no. 3, pp. 1389-1397, 2010.

[5] L. X. Zhang, Z. F. Yang, and G. Q. Chen, "Emergy analysis of cropping-grazing system in Inner Mongolia Autonomous Region, China," Energy Policy, vol. 35, no. 7, pp. 3843-3855, 2007.

[6] L. Zhang, Z. Yang, B. Chen, and G. Chen, "Rural energy in China: pattern and policy," Renewable Energy, vol. 34, no. 12, pp. 2813-2823, 2009.

[7] G. Q. Chen and B. Chen, "Extended-exergy analysis of the Chinese society," Energy, vol. 34, no. 9, pp. 1127-1144, 2009.

[8] B. Zhang and G. Q. Chen, "Physical sustainability assessment for the China society: exergy-based systems account for resources use and environmental emissions," Renewable and 
Sustainable Energy Reviews, vol. 14, no. 6, pp. 1527-1545, 2010.

[9] Z. F. Yang, M. M. Jiang, B. Chen, J. B. Zhou, G. Q. Chen, and S. C. Li, "Solar emergy evaluation for Chinese economy," Energy Policy, vol. 38, no. 2, pp. 875-886, 2010.

[10] Z. M. Chen, G. Q. Chen, J. B. Zhou, M. M. Jiang, and B. Chen, "Ecological input-output modeling for embodied resources and emissions in Chinese economy 2005," Communications in Nonlinear Science and Numerical Simulation, vol. 15, no. 7, pp. 1942-1965, 2010.

[11] H. Liao and Y. M. Wei, "China's energy consumption: a perspective from Divisia aggregation approach," Energy, vol. 35 , no. 1, pp. 28-34, 2010.

[12] J. B. Zhou, M. M. Jiang, and G. Q. Chen, "Estimation of methane and nitrous oxide emission from livestock and poultry in China during 1949-2003," Energy Policy, vol. 35, no. 7, pp. 3759-3767, 2007.

[13] X. Ji and G. Q. Chen, "Unified account of gas pollutants and greenhouse gas emissions: Chinese transportation 19782004," Communications in Nonlinear Science and Numerical Simulation, vol. 15, no. 9, pp. 2710-2722, 2010.

[14] X. H. Xia, G. T. Huang, G. Q. Chen, B. Zhang, Z. M. Chen, and Q. Yang, "Energy security, efficiency and carbon emission of Chinese industry," Energy Policy, vol. 39, no. 6, pp. 3520$3528,2011$.

[15] X. H. Xia and G. Q. Chen, "Energy abatement in Chinese industry: cost evaluation of regulation strategies and allocation alternatives," Energy Policy, vol. 45, pp. 449-458, 2012.

[16] T. R. Beard, S. B. Caudill, and D. M. Gropper, "The diffusion of production processes in the U.S. Banking industry: a finite mixture approach," Journal of Banking and Finance, vol. 21, no. 5, pp. 721-740, 1997.

[17] M. Wedel and W. S. Desarbo, "Market segment derivation and profiling via a finite mixture model framework," Marketing Letters, vol. 13, no. 1, pp. 17-25, 2002.

[18] K. K. W. Yau, A. H. Lee, and A. S. K. Ng, "Finite mixture regression model with random effects: application to neonatal hospital length of stay," Computational Statistics and Data Analysis, vol. 41, no. 3-4, pp. 359-366, 2003.

[19] K. Imai and D. Tingley, "A statistical method for empirical testing of competing theories," American Journal of Political Science, vol. 56, no. 1, pp. 218-236, 2012.

[20] P. Edussuriya, A. Chan, and A. Ye, "Urban morphology and air quality in dense residential environments in Hong Kong. Part I: district-level analysis," Atmospheric Environment, vol. 45, no. 27, pp. 4789-4803, 2011.

[21] T. Van de Voorde, W. Jacquet, and F. Canters, "Mapping form and function in urban areas: an approach based on urban metrics and continuous impervious surface data," Landscape and Urban Planning, vol. 102, no. 3, pp. 143-155, 2011.

[22] J. W. R. Whitehand, K. Gu, S. M. Whitehand, and J. Zhang, "Urban morphology and conservation in China," Cities, vol. 28, no. 2, pp. 171-185, 2011.

[23] I. Larivière and G. Lafrance, "Modelling the electricity consumption of cities: effect of urban density," Energy Economics, vol. 21, no. 1, pp. 53-66, 1999.

[24] A. S. Permana, R. Perera, and S. Kumar, "Understanding energy consumption pattern of households in different urban development forms: a comparative study in Bandung City, Indonesia," Energy Policy, vol. 36, no. 11, pp. 4287-4297, 2008.

[25] W. Wang, H. Mu, X. Kang, R. Song, and Y. Ning, "Changes in industrial electricity consumption in china from 1998 to 2007," Energy Policy, vol. 38, no. 7, pp. 3684-3690, 2010.
[26] M. Aasen, H. Westskog, H. Wilhite, and M. Lindberg, "The EU electricity disclosure from the business perspective-a study from Norway," Energy Policy, vol. 38, no. 12, pp. 7921-7928, 2010.

[27] J. Chen, "China's experiment on the differential electricity pricing policy and the struggle for energy conservation," Energy Policy, vol. 39, no. 9, pp. 5076-5085, 2011.

[28] N. Zhou, M. D. Levine, and L. Price, "Overview of current energy-efficiency policies in China," Energy Policy, vol. 38, no. 11, pp. 6439-6452, 2010.

[29] F. Halicioglu, "Residential electricity demand dynamics in Turkey," Energy Economics, vol. 29, no. 2, pp. 199-210, 2007.

[30] Y. Liu, "Exploring the relationship between urbanization and energy consumption in China using ARDL (autoregressive distributed lag) and FDM (factor decomposition model)," Energy, vol. 34, no. 11, pp. 1846-1854, 2009.

[31] D. Wiesmann, I. Lima Azevedo, P. Ferrão, and J. E. Fernández, "Residential electricity consumption in Portugal: findings from top-down and bottom-up models," Energy Policy, vol. 39, no. 5, pp. 2772-2779, 2011.

[32] E. Ziramba, "The demand for residential electricity in South Africa," Energy Policy, vol. 36, no. 9, pp. 3460-3466, 2008.

[33] V. Bianco, O. Manca, S. Nardini, and A. A. Minea, "Analysis and forecasting of nonresidential electricity consumption in Romania," Applied Energy, vol. 87, no. 11, pp. 3584-3590, 2010.

[34] M. Bessec and J. Fouquau, "The non-linear link between electricity consumption and temperature in Europe: a threshold panel approach," Energy Economics, vol. 30, no. 5, pp. 27052721, 2008.

[35] T. M. Lai, W. M. To, W. C. Lo, and Y. S. Choy, "Modeling of electricity consumption in the Asian gaming and tourism center-Macao SAR, People's Republic of China," Energy, vol. 33, no. 5, pp. 679-688, 2008.

[36] P. J. Burke, "Income, resources, and electricity mix," Energy Economics, vol. 32, no. 3, pp. 616-626, 2010.

[37] A. P. Dempster, N. Laird, and D. B. Rubin, "Maximum likelihood estimation from incomplete data using the EM algorithm (with discussion)," Journal of the Royal Statistical Society B, vol. 39, pp. 1-38, 1977.

[38] G. Mclachlan and T. Krishnan, The EM Algorithm and Extensions, John Wiley \& Sons, New York, NY, USA, 1997.

[39] G. McLachlan and D. Peel, Finite Mixture Models, Wiley Series in Probability and Statistics, New York, NY, USA, 2000.

[40] S. Frühwirth-Schnatter, Finite Mixture and Markov Switching Models, Springer, New York, NY, USA, 2007.

[41] B. Grün and F. Leisch, "Flexmix version 2: finite mixtures with concomitant variables and varying and constant parameters," Journal of Statistical Software, vol. 28, no. 4, pp. 1-35, 2008.

[42] H. Akaike, "Information theory and an extension of the maximum likelihood principle," in Proceedings of the 2nd International Symposium on Information Theory, B. N. Petrov and F. Csáki, Eds., pp. 267-281, Académiai Kiadó, Budapest, Hungary, 1973.

[43] G. Schwarz, "Estimating the dimension of a model," The Annals of Statistics, vol. 6, pp. 461-464, 1978.

[44] E. J. Hannan and B. G. Quinn, "The determination of the order of an autoregression," Journal of the Royal Statistical Society B, vol. 41, pp. 190-195, 1979.

[45] G. Celeux and G. Soromenho, "An entropy criterion for assessing the number of clusters in a mixture model," Journal of Classification, vol. 13, no. 2, pp. 195-212, 1996. 
[46] C. Biernacki and G. Govaert, "Using the classification likelihood to choose the number of clusters," Computing Science and Statistics, vol. 29, pp. 451-457, 1997.

[47] C. Biernacki, G. Celeux, and G. Govaert, "Assessing a mixture model for clustering with the integrated completed likelihood," IEEE Transactions on Pattern Analysis and Machine Intelligence, vol. 22, no. 7, pp. 719-725, 2000.

[48] J. Bai and S. Ng, "Confidence intervals for diffusion index forecasts and inference for factor-augmented regressions," Econometrica, vol. 74, no. 4, pp. 1133-1150, 2006.

[49] S. Ng and J. Bai, "Selecting instrumental variables in a data rich environment," Journal of Time Series Econometrics, vol. 1, no. 1, article 4, 2009.

[50] E. L. Glaeser and M. Kahn, "Sprawl and Urban Growth," in The Handbook of Regional and Urban Economics, V. Henderson and J. Thisse, Eds., North Holland, Amsterdam, The Netherlands, 2004.

[51] SERC (State Electricity Regulatory Commission), "The regulatory report on the execution of electricity price and the settlement of electricity charges in 2009," http://www.serc.gov. cn/zwgk/jggg/201009/W020100913435310821659.doc. 

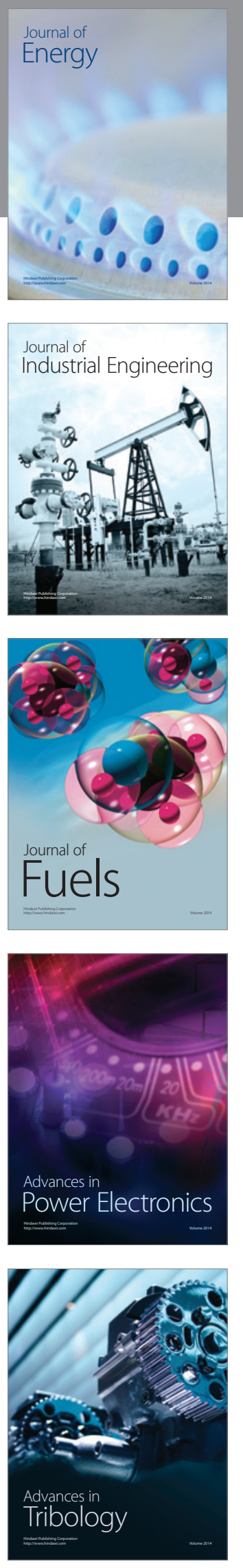
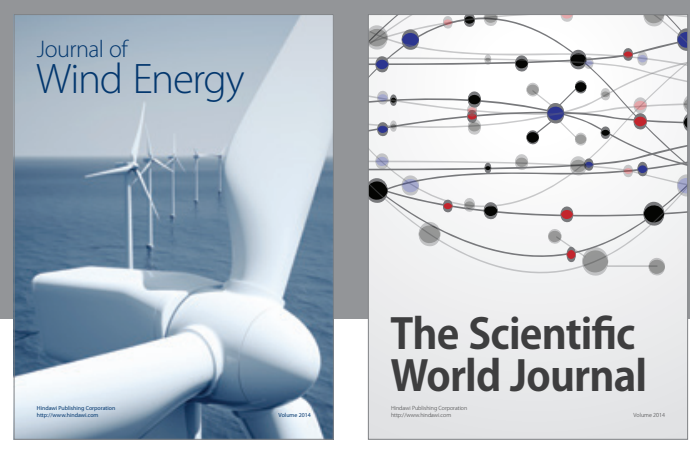

The Scientific World Journal

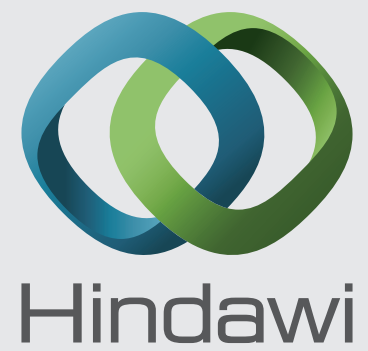

Submit your manuscripts at http://www.hindawi.com
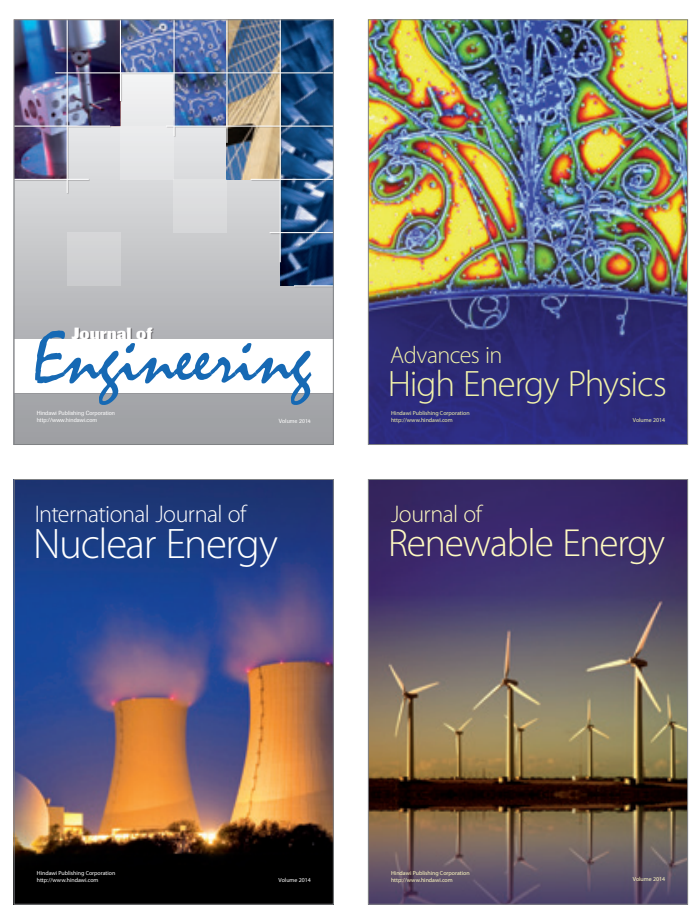

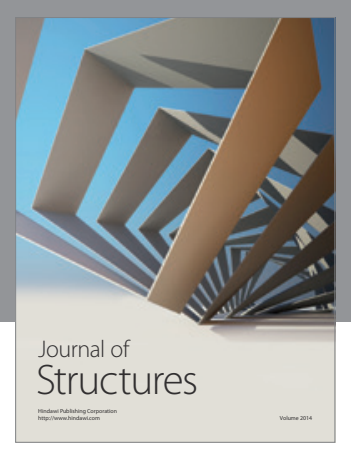

Rotating
Mechinery
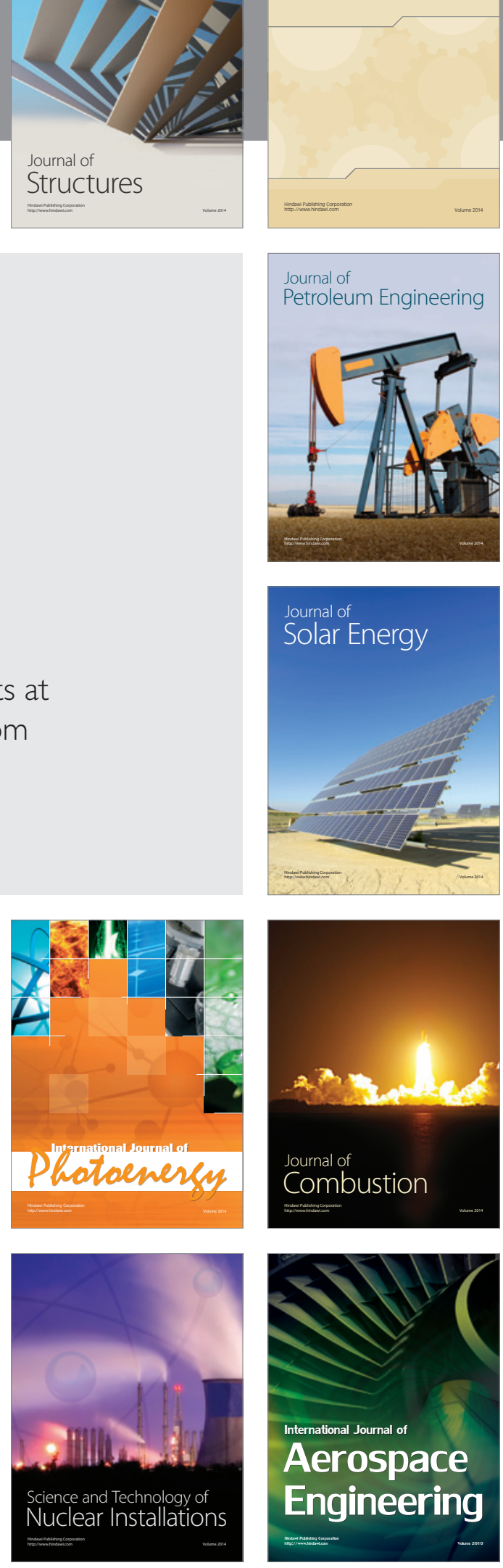